Maastricht University Medical Centre, Maastricht, The Netherlands. ${ }^{5}$ Dept of Medical Microbiology, Radboud University Medical Centre, Nijmegen, The Netherlands. ${ }^{6}$ Dept of Toxicology, School for Nutrition, Toxicology, and Metabolism, Maastricht University Medical Centre, Maastricht, The Netherlands. ${ }^{7}$ Dept of General Practice, School for Public Health and Primary Care, Maastricht University Medical Centre, Maastricht, The Netherlands.

Correspondence: Ester M.M. Klaassen, Dept of Paediatric Respiratory Medicine, Maastricht University Medical Centre, P.O. Box 5800, 6202 AZ Maastricht, The Netherlands. E-mail: e.klaassen@student.maastrichtuniversity.nl

Received: Jan 302014 | Accepted after revision: April 222014 | First published online: July 172014

Conflict of interest: None declared.

\title{
References
}

Sly PD, Holt PG. Role of innate immunity in the development of allergy and asthma. Curr Opin Allergy Clin Immunol 2011; 11: 127-131.

2 Chang JC, Wang L, Chen RF, et al. Perinatal gene-gene and gene-environment interactions on IgE production and asthma development. Clin Dev Immunol 2012; 2012: 270869.

3 Rigoli L, Briuglia S, Caimmi S, et al. Gene-environment interaction in childhood asthma. Int J Immunopathol Pharmacol 2011; 24: 41-47.

4 Bottema RW, Kerkhof M, Reijmerink NE, et al. Gene-gene interaction in regulatory T-cell function in atopy and asthma development in childhood. J Allergy Clin Immunol 2010; 126: 338-346.

5 Tesse R, Pandey RC, Kabesch M. Genetic variations in toll-like receptor pathway genes influence asthma and atopy. Allergy 2011; 66: 307-316.

6 van de Kant KD, Klaassen EM, Jobsis Q, et al. Early diagnosis of asthma in young children by using non-invasive biomarkers of airway inflammation and early lung function measurements: study protocol of a case-control study. BMC Public Health 2009; 9: 210.

7 Worldwide variation in prevalence of symptoms of asthma, allergic rhinoconjunctivitis, and atopic eczema: ISAAC. The International Study of Asthma and Allergies in Childhood (ISAAC) Steering Committee. Lancet 1998; 351: $1225-1232$.

8 Klaassen EM, van Kant KD, Jobsis Q, et al. Symptoms, but not a biomarker response to inhaled corticosteroids, predict asthma in preschool children with recurrent wheeze. Mediators Inflamm 2012; 2012: 162571.

9 Bisgaard $\mathrm{H}$, Hermansen MN, Buchvald F, et al. Childhood asthma after bacterial colonization of the airway in neonates. N Engl J Med 2007; 357: 1487-1495.

10 Holgate ST. Has the time come to rethink the pathogenesis of asthma? Curr Opin Allergy Clin Immunol 2010; 10: $48-53$.

\section{Differential expression of IL-33 and HMGB1 in the lungs of stable cystic fibrosis patients}

To the Editor:

In cystic fibrosis (CF), repeated inflammation of the lung leads to progressive damage of lung tissue $[1,2]$. In case of tissue destruction or in response to inflammation, necrotic cells release danger signals. These proteins trigger inflammatory responses, contribute to elimination of pathogens and induce tissue repair [3]. Imbalanced or uncontrolled release of such mediators may amplify inflammatory responses that in turn facilitate tissue damage.

Interleukin (IL)-33 and high-mobility group box 1 protein (HMGB1) are both considered to be such "alarmins" [3]. Given the T-helper cell (Th)17/Th2 nature of lung inflammation in asymptomatic CF individuals and its linkage to CF-associated pathogens [1, 2], we hypothesised that IL-33 and HMGB1 may contribute to the local sustained inflammatory processes.

Both these alarmins are dual-function proteins, as they are nuclear factors regulating gene expression and also act as cytokines when released from cells [3]. In contrast to ubiquitously expressed HMGB1, IL-33 is mainly expressed in barrier-function-like epithelial cells [3]. IL-33 is mainly linked to augmentation and initiation of Th2-type inflammation but might also antagonise overwhelming tissue inflammation linked to pathogens [4-6]. HMGB1 acts as a cytokine, which contributes to activation of innate receptors, matures dendritic cells (DCs), contributes to migration of DCs and amplifies inflammation itself via induction 
of pro-inflammatory cytokines like tumour necrosis factor (TNF)- $\alpha$, IL-6, IL-1 $\beta$ and macrophage inflammatory protein (MIP) 1 [7].

To directly compare the contributions of released IL-33 and HMGB1 in CF lung inflammation, we assessed protein levels in bronchoalveolar lavage fluid (BALF) of 44 CF patients and 10 non-CF controls with recurrent pulmonary infections. To increase the homogeneity of the CF population, patients with clinical signs of exacerbation (decline of lung function $>10 \%$, start of an antibiotic therapy, increase in coughing, clinical signs of infection, or signs of infection in terms of C-reactive protein elevation or differential counts) were excluded from analysis. In brief, BALF was obtained from patients who underwent bronchoscopy at the CF centre of the Dept of Pediatrics and Adolescent Medicine, Medical University of Vienna (Vienna, Austria) from July 2009 to December 2011, as described by TiRINGer et al. [1]. Sampling and processing of BALF and multiplex sandwich ELISA (IL-1 $\beta$, IL-5, IL-6, IL-8, IL-13, IL-17A, IL-23, interferon (IFN) $-\gamma$, thymus and activation-regulated chemokine (TARC), TNF- $\alpha$, macrophage-derived chemokine (MDC), thymic stromal lymphopoietin (TSLP), IL-17E and IL-12p70) were performed as previously described and correlated with IL-33 and HMGB1 values [1]. IL-33 (eBioscience, San Diego, CA, USA) and HMGB1 (IBL International, Hamburg, Germany) were measured via sandwich ELISA according to the manufacturer's instructions and absolute values were corrected according to the concentration factor. Diagnosis of CF was confirmed by repeated sweat tests and the type of mutation was defined by genetic testing. Parenchymal and bronchial epithelial tissue samples from end-stage disease patients was obtained at the time of transplantation from explanted lungs at the Dept of Thoracic Surgery, Medical University of Vienna from August 2009 to August 2011. Clinically stable CF patients and controls were matched according to age, sex and body mass index. PCR primers and probes were designed based on the sequences reported in GenBank with the Primer Express software version 1.2 (Applied Biosystems, Foster City, CA, USA) and were as follows: IL-33 forward 5'-GTT ACT TTA GGA GAG AAA CCA CCA AA-3', IL-33 reverse 5'-TTG ACA GGC AGC GAG TAC CA-3', elongation factor (EF) $1 \alpha$ forward 5'-CTG AAC CAT CCA GGC CAA AT-3', EF1 $\alpha$ reverse 5'-GCC GTG TGG CAA TCC AAT-3'. Relative changes in tissue expression of genes between patient groups were calculated as follows: the sample with the lowest amount of the respective gene was set as internal standard and relative expression was calculated by $2^{\text {( } \Delta \text { Ct sample of interest- } \Delta \text { Ct lowest sample })}$. Data are expressed as fold expression of the respective sample. The amplification efficacy was initially tested by serial dilution of the cDNA. The generation of relevant primer-dimer formations was excluded.

We found divergent prominence of IL-33 and HMGB1 in local inflammatory processes in CF lungs. Levels of IL-33 were significantly higher in clinically stable CF patients compared with non-CF controls $(\mathrm{p}<0.05)$, whereas HMGB1 levels were significantly higher in non-CF controls with recurrent infections $(p=0.02)$ (fig. $1 \mathrm{a}$ and $\mathrm{b})$. In CF patients, levels of IL-33 correlated with levels of IL-8 $(\mathrm{r}=0.51 ; \mathrm{p}<0.01)$ and IL-13 $(\mathrm{r}=0.53 ; \mathrm{p}<0.01)$ and, to a lesser degree, with IL-12p70 $(\mathrm{r}=0.43 ; \mathrm{p}<0.05)$, confirming the reported Th2enhancing and monocyte-recruiting properties of IL-33 and supporting a role in epithelial inflammation via IL-8 $[1,6]$. In clinically stable CF patients who were able to perform lung function tests $(n=13)$, levels of IL-33 in BALF negatively correlated with forced vital capacity $(\mathrm{r}=0.58 ; \mathrm{p}<0.05)$, suggesting another role for IL-33 apart from pathogen-related infection and tissue destruction. HMGB1 negatively correlated with levels of IL-1 $\beta(\mathrm{r}=-0.46 ; \mathrm{p}<0.01)$ [8].

In addition, we assessed expression levels of IL-33 in parenchymal and bronchial epithelial lung tissue from explanted end-stage lungs of nine CF patients and 11 controls (lung fibrosis and primary pulmonary hypertension) via real-time RT-PCR [1]. In line with the aforementioned results, IL-33 mRNA expression was higher in CF patients compared with non-CF controls (fig. 1c and d), although this did not reach statistical significance.

A role for HMGB1 in CF background inflammation and leukocyte recruitment has been described [9]. It may appear surprising that HMGB1 is lower in BALF of CF patients compared with non-CF patients with recurrent infections. However, compared with reported values in healthy controls $\left(1-8 \mathrm{ng} \cdot \mathrm{mL}^{-1}\right)$, it is elevated [2]. Moreover, the control group used by Rowe et al. [9] consisted of healthy individuals, compared with the clinically stable individuals with recurrent pulmonary infections in this study. In addition, binding of HMGB1 to bacterial compounds is reported and greater abundance of such components in the lungs of CF patients compared with non-CF controls seems feasible [7]. The latter may explain the inverse relationship between IL-1 $\beta$ and HMGB1 levels in BALF. Furthermore, cholinergic agonists, which are part of the CF basic inhalant therapy, inhibit HMGB1 [10].

IL-33, in contrast, reflects more the activation of the immune system and cell damage and bridges innate and adaptive immunity. The Th2-skewed cytokine profile in CF has been linked to a deficiency in producing IFN- $\gamma$ [11]. This has also been observed in response to IL-33 [6]. Given the fact that Th2-type cells upregulate the IL-33 receptor ST2, a good responsiveness to IL-33 may further add to pathophysiology in CF. Furthermore, IL-33 mediates neutrophil influx [5], a characteristic feature in CF. Exposure to 

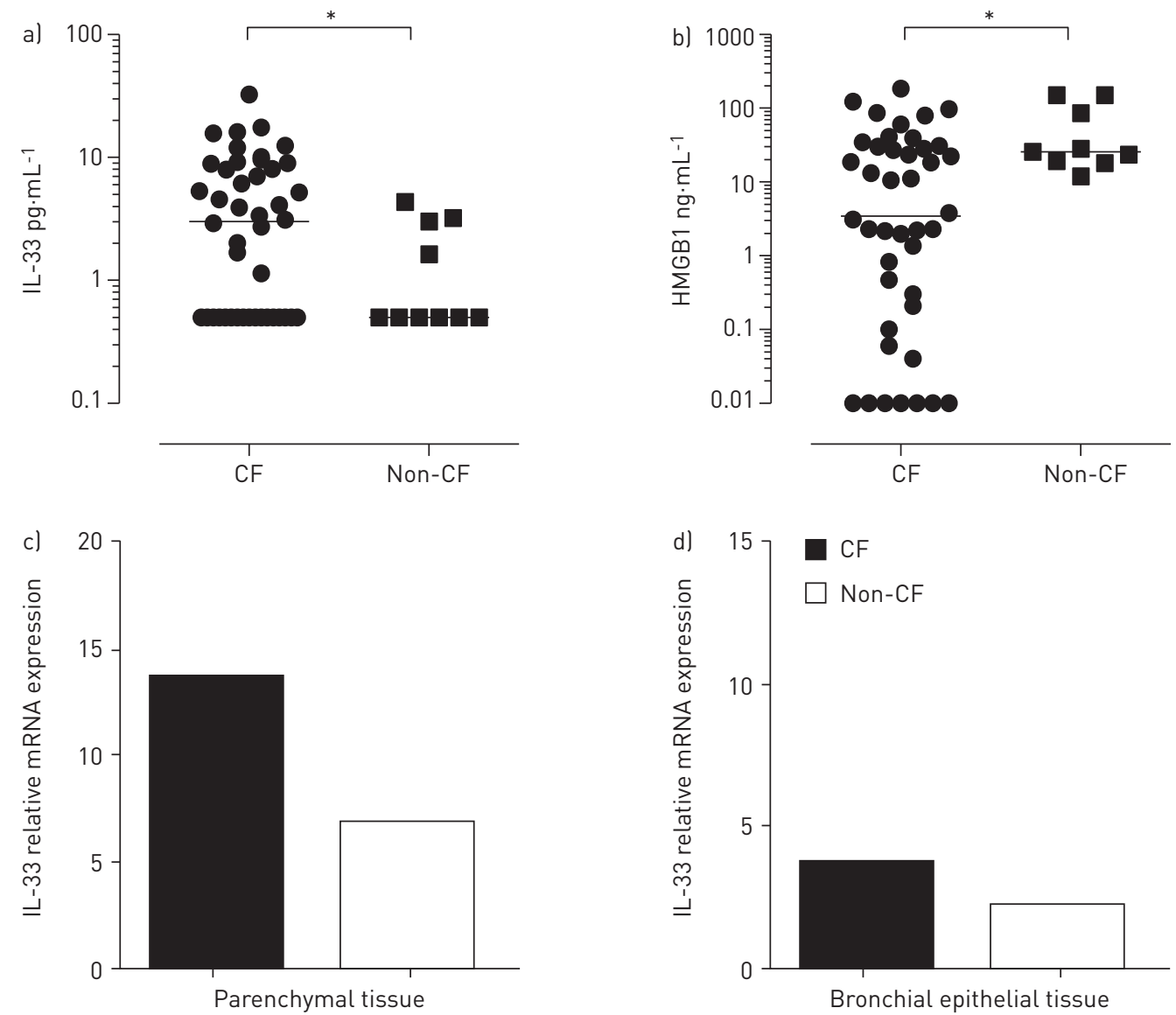

FIGURE 1 Interleukin (IL)-33 and high-mobility group box 1 protein (HMGB1) in cystic fibrosis (CF) lungs. Levels of a) IL-33 and b) HMGB1 were measured in bronchoalveolar lavage fluid via ELISA. a) IL-33 was significantly elevated in clinically stable CF patients $(n=32)$ compared to non-CF controls $(n=10)$, whereas b) HMGB1 was higher in the control group (CF group $n=32$, controls $n=9$ ). mRNA expression levels of IL-33 were measured in c) parenchymal and d) bronchial epithelial lung tissue of CF patients $(n=9)$ and non-CF controls (primary pulmonary hypertension and lung fibrosis, $\mathrm{n}=11$ ) via real-time RT-PCR. The sample with the lowest amount of the respective gene was set as internal standard and relative expression was calculated by $2^{(\Delta \mathrm{Ct} \text { sample of interest- } \Delta \mathrm{Ct} \text { lowest sample) }}$. Data are expressed as fold expression of the respective sample. ${ }^{*}$ : $\mathrm{p}<0.05$, Mann-Whitney U-test.

Pseudomonas aeruginosa has been shown to induce IL-33 but not HMGB1 mRNA. This is in line with our data, and also with HARTL et al. [12], linking chronic P. aeruginosa infection with augmented Th2 responses. In addition, a linkage between IL-33 mRNA expression and the absence of cystic fibrosis transmembrane conductance regulator (CFTR) has been found [5]. This study significantly adds to current knowledge by confirming IL-33 protein in BALF, in the context of CF.

Taken together, IL-33 may significantly contribute to Th2 responses observed in CF lungs. IL-33 augments Th2-driven inflammation and thereby facilitates chronic inflammation in CF lungs, by an inefficient suppression of inflammatory responses. Thus, IL-33 might influence not only CF lung disease but also other CF-related pathologies. The differential roles of IL-33 and HMGB1 could serve as a model for a better understanding of the complex relationship between innate and adaptive immunity.

@ERSpublications

IL-33 levels in BALF may indicate their contribution to Th2 inflammatory responses in CF lungs http://ow.ly/wAiZX

Kerstin Tiringer ${ }^{1}$, Angela Treis ${ }^{2}$, Stefan Kanolzer ${ }^{1}$, Carina Witt ${ }^{1}$, Bahil Ghanim ${ }^{3}$, Saskia Gruber ${ }^{1}$, Klara Schmidthaler ${ }^{1}$, Sabine Renner ${ }^{1}$, Eleonora Dehlink ${ }^{1}$, Edith Nachbaur ${ }^{1}$, Thomas Frischer ${ }^{1}$, Walter Klepetko ${ }^{3}$, Cezmi A. Akdis ${ }^{2}$,

Zsolt Szépfalusi ${ }^{1}$ and Thomas Eiwegger ${ }^{1}$

${ }^{1}$ Dept of Pediatrics and Adolescent Medicine, Medical University of Vienna, Vienna, Austria. ${ }^{2}$ Swiss Institute of Allergy and Asthma Research (SIAF), University of Zurich, Zurich, Switzerland. ${ }^{3}$ Dept of Cardiothoracic Surgery, Medical University of Vienna, Vienna, Austria. 
Correspondence: Thomas Eiwegger, Dept of Pediatrics and Adolescent Medicine, Medical University of Vienna, Waehringer Guertel 18-20, 1090 Vienna, Austria. E-mail: thomas.eiwegger@meduniwien.ac.at

Received: March 102014 | Accepted after revision: April 142014 | First published online: June 252014

Support statement: Supported by funds from the Oesterreichische Nationalbank (Anniversary Fund, project number $13846 \mathrm{ONB}$ ) and the Medical Scientific Fund of the Mayor of the City of Vienna (number 11013).

Conflict of interest: Disclosures can be found alongside the online version of this article at erj.ersjournals.com

\section{References}

1 Tiringer K, Treis A, Fucik P, et al. A Th17- and Th2-skewed cytokine profile in cystic fibrosis lungs represents a potential risk factor for Pseudomonas aeruginosa infection. Am J Respir Crit Care Med 2013; 187: 621-629.

2 Liou TG, Adler FR, Keogh RH, et al. Sputum biomarkers and the prediction of clinical outcomes in patients with cystic fibrosis. PLoS One 2012; 7: e42748.

3 Hirsiger S, Simmen HP, Werner CM, et al. Danger signals activating the immune response after trauma. Mediator Inflamm 2012; 2012: 315941.

4 Akdis M, Burgler S, Crameri R, et al. Interleukins, from 1 to 37, and interferon- $\gamma$ : receptors, functions, and roles in diseases. J Allergy Clin Immunol 2011; 127: 701-721.e70.

5 Roussel L, Farias R, Rousseau S. IL-33 is expressed in epithelia from patients with cystic fibrosis and potentiates neutrophil recruitment. J Allergy Clin Immunol 2013; 131: 913-916.

6 Schmitz J, Owyang A, Oldham E, et al. IL-33, an interleukin-1-like cytokine that signals via the IL-1 receptorrelated protein ST2 and induces T helper type 2-associated cytokines. Immunity 2005; 23: 479-490.

7 Yanai H, Ban T, Taniguchi T. High-mobility group box family of proteins: ligand and sensor for innate immunity. Trends Immunol 2012; 33: 633-640.

8 Abraham E, Arcaroli J, Carmody A, et al. HMG-1 as a mediator of acute lung inflammation. J Immunol 2000; 165: 2950-2954.

9 Rowe SM, Jackson PL, Liu G, et al. Potential role of high-mobility group box 1 in cystic fibrosis airway disease. Am J Respir Crit Care Med 2008; 178: 822-831.

10 Wang $\mathrm{H}$, Liao $\mathrm{H}$, Ochani $\mathrm{M}$, et al. Cholinergic agonists inhibit HMGB1 release and improve survival in experimental sepsis. Nat Med 2004; 10: 1216-1221.

11 Brazova J, Sediva A, Pospisilova D, et al. Differential cytokine profile in children with cystic fibrosis. Clin Immunol 2005; 115: 210-215.

12 Hartl D, Griese M, Kappler M, et al. Pulmonary Th2 response in Pseudomonas aeruginosa-infected patients with cystic fibrosis. J Allergy Clin Immunol 2006; 117: 204-211.

\section{Interferon- $\gamma$ responses to Mycobacterium tuberculosis-specific antigens in diabetes mellitus}

To the Editor:

Although diabetes mellitus has long been recognised as a risk factor for tuberculosis, it was only recently that strong evidence for this emerged [1]. Persons with diabetes mellitus have a two or three times higher risk of developing tuberculosis disease than nondiabetics; those with tuberculosis and diabetes mellitus have a four times higher risk of death during tuberculosis treatment and a higher risk of tuberculosis relapse [2, 3].

Diabetics therefore constitute a target group in whom the identification of latent tuberculosis infection (LTBI) and its treatment may potentially be an important strategy for tuberculosis elimination $[4,5]$. Interferon- $\gamma$ release assays (IGRAs) are immunodiagnostic tests for identification of LTBI. These tests have shown superior specificity and positive predictive value for progression to active disease over the tuberculin skin test [6-9]. Although the IGRAs do not distinguish active from latent tuberculosis [10, 11], they are often done as part of the work-up for active tuberculosis in cases where diagnostic uncertainty exists. To date, there is scant information in the literature regarding the performance of these assays in diabetics.

In a previous report in which we evaluated the T-SPOT.TB (Oxford Immunotec, Abingdon, UK) and QuantiFERON In-Tube (QFT-IT) (Cellestis, Melbourne, Australia) assays in a head-to-head manner in 270 culture-confirmed pulmonary tuberculosis patients, we had found undiminished sensitivity of these assays in the presence of diabetes mellitus [12]. WALSH et al. [13] have also reported that diabetes did not affect the performance of the second-generation QuantiFERON TB Gold (QFT-G) and T-SPOT.TB [13]. 